\title{
Perkembangan Riset Bidang Manajemen Rantai Pasok Berkelanjutan
}

\author{
Muh. Hisjam*) \\ Program Studi Teknik Industri, Fakultas Teknik, Universitas Sebelas Maret, Jl. Ir. Sutami 361A, Surakarta, 57126, \\ Indonesia
}

\section{DOI: 10.20961/performa.17.2.20390}

\begin{abstract}
Abstrak
Keberlanjutan (sustainability) merupakan isu penting yang sering muncul belakangan ini. Manajemen Rantai Pasok Berkelanjutan (Sustainable Supply Chain Management, SSCM) yang merupakan pengembangan dari kajian manajemen rantai pasok dengan menggabungkannya dengan konsep keberlanjutan juga menjadi salah satu tren riset dalam bidang rantai pasok. Pentingnya kajian SSCM ditunjukkan dengan peningkatan jumlah publikasi dalam bidang ini. Makalah ini memberi manfaat bagi peneliti di bidang ini untuk mengetahui gambaran perkembangan keilmuan di bidang ini, tren risetnya, dan arah penelitian yang sebaiknya dikaji. Metode kuantitatif dengan statistik deskriptif digunakan untuk mengolah data seluruh luaran publikasi SSCM yang diindeks oleh SCOPUS sampai dengan periode April 2017. Pengolahan data juga dilakukan dengan membandingkan perkembangan ilmu SSCM di dunia, dan Indonesia. Analisis perbandingan perkembangan riset SCM berdasarkan wilayah, subjek, kata kunci juga dibahas pada makalah ini. Secara khusus, tren riset SSCM di Indonesia juga dianalisis berdasarkan subject area terkait yang digunakan untuk memecahkan masalah SSCM. Tren keilmuan SSCM juga disarikan dari beberapa literature review yang terpilih.
\end{abstract}

Kata kunci: perkembangan riset, manajemen rantai pasok berkelanjutan, keberlanjutan.

\begin{abstract}
Sustainability is an important issue that frequently arises lately. Sustainable Supply Chain Management (SSCM) which is a development of the study of supply chain management by combining it with the concept of sustainability is also one of the research trends in the supply chain field. The importance of the SSCM study is indicated by the increase in the number of publications in this field. This paper is useful for researchers to know the description of scientific developments in this field, the research trends, and the direction of research that should be studied. Quantitative methods with descriptive statistics are used to process the entire output of SSCM publications indexed by SCOPUS until the period of April 2017. Data processing is also done by comparing the development of SSCM knowledge worldwide and in Indonesia. Comparative analysis of SCM research developments by region, subject, keywords are also discussed in this paper. In particular, SSCM research trends in Indonesia were also analyzed based on the related subject areas used to solve SSCM problems. SSCM scientific trends are also extracted from selected literature reviews.
\end{abstract}

Keywords: development of research, sustainable supply chain management, sustainability.

${ }^{+}$Topik makalah ini telah disampaikan oleh Penulis sebagai Pembicara Utama pada $4^{\text {th }}$ Industrial Engineering Conference 2017 (IDEC 2017), Hotel Alana Surakarta, Senin 8 Mei 2017.

\section{Pendahuluan}

Isu-isu tentang keberlanjutan telah menjadi isu penting akhir-akhir ini. Istilah keberlanjutan yang dimaksud dalam makalah ini mengacu pada definisi pembangunan berkelanjutan (sustainable development) dari Brundtland Report. Brundtland Report merupakan laporan sebuah komisi dalam United Nations World Commission on Environment and Development (WCED), yang didalamnya didefinisikan pembangunan berkelanjutan sebagai pembangunan yang memenuhi kebutuhan saat ini tanpa mengorbankan kemampuan generasi mendatang untuk memenuhi kebutuhan mereka sendiri (Brundtland Commission, 1987).

Pembangunan berkelanjutan mencakup tiga aspek keberlanjutan, yaitu ekonomi, sosial dan lingkungan yang sering diistilahkan dengan triple bottom line (Ahi dan Searcy, 2013; Hollos dkk, 2011; Govindan dkk, 2013).

Masalah-masalah tentang sustainability merupakan tema menarik dari segi kajian keilmuan maupun dari segi bisnis (Nagurney dan Nagurney, 2010; Hahn dan Kühnen, 2013; Brandenburg dkk, 2014). Ini terbukti

*Korespondensi : mhisjam@yahoo.com, hisjam@staff.uns.ac.id 
dengan pencarian dokumen di website SCOPUS (www.scopus.com) pada tanggal 30 April 2017 menggunakan kata kunci yang relevan dengan tema keberlanjutan diketahui adanya peningkatan yang kontinyu dari jumlah publikasinya, misalkan dengan kata kunci "sustainability OR sustainable" (keberlanjutan atau berkelanjutan) serta "supply chain management" digabung dengan "sustainability OR sustainable". Hal ini menunjukkan bahwa topik dengan tema keberlanjutan merupakan topik yang menarik secara kajian ilmiah.

Manajemen Rantai Pasok Berkelanjutan (Sustainable Supply Chain Management, SSCM) melibatkan entitas-entitas dari siklus pengadaan bahan, siklus produksi, sampai siklus distribusi dengan kepentingan yang berbeda-beda dengan tujuan utamanya untuk memenuhi kebutuhan konsumen akhir. Hubungan antar entitas tersebut saling mempengaruhi, sehingga keputusan suatu entitas akan berpengaruh terhadap entitas lain, misal: tuntutan konsumen terhadap produk yang ramah lingkungan harus dipenuhi oleh semua entitas sampai pemasok. Antar ketiga aspek tersebut juga saling berpengaruh terhadap pencapaian tujuan dari masing-masing aspek tersebut. Hal ini membuat permasalahan yang ada pada SSCM menjadi kompleks.

Pada makalah ini dibahas perkembangan ilmu SSCM secara kuantitatif baik di dunia maupun di Indonesia. Makalah ini memberi gambaran perkembangan keilmuan di bidang SSCM, kecenderungan area kajian penelitian terdahulu serta arah penelitian di bidang ini. Dalam makalah ini disampaikan rangkuman data-data kualitatif terkait riset tentang SSCM di dunia beserta subjek dan tema apa yang paling banyak dibahas. Di bagian akhir akan dibahas bagaimana gambaran perkembangan keilmuan SSCM di Indonesia.

\section{Manajemen Rantai Pasok Berkelanjutan}

Terdapat banyak definisi tentang Manajemen Rantai Pasok Berkelanjutan (Sustainable Supply Chain Management, SSCM) dan definisi yang cukup komprehensif yaitu Seuring (2013) dan Ahi dan Searcy (2013). Seuring (2013) mendefisikannya sebagai manajemen aliran material, informasi dan modal yang merupakan kerjasama antar perusahaan sepanjang rantai pasok dengan mengintegrasikan tujuan-tujuan yang mencakup ketiga dimensi pembangunan berkelanjutan yaitu ekonomi, lingkungan, dan sosial yang dijabarkan dari tuntutan-tuntutan pelanggan dan pemangku kepentingan. Sedangkan definisi dari Ahi dan Searcy (2013) adalah penciptaan rantai pasok yang dikoordinasikan melalui integrasi sukarela dengan pertimbangan ekonomi, sosial dan lingkungan dengan sistem bisnis antar-organisasi kunci yang dirancang untuk mengelola bahan, informasi, dan arus modal secara efisien dan efektif yang berkaitan dengan pengadaan, produksi, dan distribusi produk atau jasa dalam rangka memenuhi persyaratan pemangku kepentingan dan meningkatkan profitabilitas, daya saing, dan ketahanan organisasi dalam jangka pendek dan jangka panjang.

Kajian SSCM dapat digunakan untuk meningkatkan keterkaitan suatu sistem industri sehingga menghasilkan nilai tambah dari ketiga aspek keberlanjutan. Penerapan SSCM dalam industri telah memberikan manfaat terkait ketiga aspek keberlanjutan (Høgevold, 2011; Jakhar, 2015; Gimenez dkk 2012). Hall dkk (2011) dan Pagell \& Shevchenko (2014) menyatakan beberapa hal yang menunjukkan pentingnya penerapan SSCM dalam bisnis. Masing-masing tujuan dari aspek ekonomi, sosial, dan lingkungan diusahakan dicapai dan diupayakan tanpa efek yang merugikan dalam aspek/dimensi lain sehingga dapat mengarah pada SSCM yang lebih berkelanjutan (Piotrowicz dalam Cetinkaya dkk, 2011).

\subsection{Aspek Ekonomi SSCM}

Beberapa ukuran kinerja aspek ekonomi ini antara lain kualitas, tingkat responsivitas, dan efisiensi. Kualitas tersebut dapat diukur misalnya dengan seperti survei pelanggan. Tingkat responsivitas ditunjukkan seberapa cepat kebutuhan pelanggan dan perubahan yang terjadi di luar perusahaan dapat ditanggapi. Ukuran tingkat responsivitas ini terkait ketersediaan produk di sepanjang SC. Efisiensi terkait dengan pemangkasan biaya, peningkatan penggunaan sumber daya, dan pengurangan waktu proses. (Piotrowicz dalam Cetinkaya dkk, 2011).

Beberapa indikator aspek ekonomi dalam penelitian SSCM antara lain:

a. Lindner dkk (2010), menggunakan biaya produksi.

b. Rondon dkk (2010), menggunakan kriteria keuntungan.

c. Gopal dan Thakkar (2015), menggunakan kriteria antara lain berbagai jenis biaya dan peningkatan penjualan.

\subsection{Aspek Sosial SSCM}

Aspek sosial diwujudkan antara lain terkait kesehatan dan keselamatan, dampak terhadap pekerja dan kebisingan yang timbul. Sebagai ukuran kesehatan dan keselamatan misalnya jumlah dan tipe kecelakaan kerja. Jumlah pekerja yang dapat diserap, pelatihan yang diterima pekerja dan keamanan pekerjaan juga bisa menjadi 
ukuran aspek sosial. Kebisingan yang timbul juga merupakan dampak sosial yang mungkin muncul (Piotrowicz dalam Cetinkaya dkk, 2011).

Beberapa indikator aspek sosial dalam penelitian SSCM antara lain:

a. Lindner dkk (2010), kriteria sosialnya yaitu keselamatan dan kesehatan kerja.

b. Hsueh (2015), CSR merupakan salah satu kriteria sosial yang digunakan.

c. Ahi dan Searcy (2015), kriteria sosialnya antara lain kesehatan dan keselamatan kerja, serta bagi keuntungan kepada komunitas terdampak.

d. Gopal dan Thakkar (2015), menggunakan kriteria antara lain: kepuasan konsumen dan kesejahteraan karyawan.

\subsection{Aspek Lingkungan SSCM}

Aspek lingkungan terkait dampak perusahaan terhadap lingkungan alam, antara lain meminimumkan emisi $\mathrm{CO} 2$, penggunaan sumber daya alam dan limbah serta memaksimumkan daur ulangnya (Piotrowicz dalam Cetinkaya dkk, 2011).

Beberapa penelitian tentang SSCM menggunakan indikator aspek lingkungan:

a. Lindner dkk (2010) salah satu kriterianya stok karbon.

b. Blicharska dkk (2012) kriterianya antara lain restorasi dan konservasi hutan.

c. Chi (2011) dengan salah satu kriterianya minimasi penggunaan bahan baku.

d. Nepstad dkk (2013), meminimasi emisi dan deforestasi adalah beberapa kriterianya.

e. Gopal dan Thakkar (2015), menggunakan kriteria antara lain: pengurangan emisi dan perbaikan efisiensi.

\section{Metodologi}

\subsection{Studi Komparatif Publikasi SSCM}

Metode yang digunakan mengacu pada Halim (2010) dengan tahapan penentuan journal selection, time horizon, article selection dan analysis. Pada makalah ini, journal selection tidak dilakukan karena sumber utama yang digunakan adalah website SCOPUS (www.scopus.com), sehingga jurnal yang digunakan hanyalah jurnal yang diindex oleh SCOPUS. SCOPUS dipilih sebagai basis pencarian dokumen, karena SCOPUS merupakan website dengan basis data literatur ber-peer-reviewed yang terbesar di dunia. Dibandingkan dengan website pengindeks dokumen yang lain, SCOPUS mempunyai kelebihan-kelebihan kemudahan dalam pencarian dokumen dibandingkan dengan website pengindeks lainnya (Burnham, 2006; Fingerman, 2006). Kekurangan dari metode ini, tentu dokumen yang terindeks di pengindeks lain (seperti web of science) tetapi tidak diindeks SCOPUS tidak termasuk dokumen yang dianalisis. Kekurangan yang lain, yaitu dokumen yang terpilih sangat tergantung pada bagaimana query yang dipilih.

\subsubsection{Pemilihan Sumber}

Berdasarkan pencarian di website SCOPUS diperoleh dokumen-dokumen mengenai SSCM di dunia dengan menggunakan kata kunci tertentu dan jangka waktu tertentu. Data yang ditampilkan berdasarkan akses yang dilakukan ke website SCOPUS pada tanggal 30 April 2017.

\subsubsection{Horison Waktu}

Horison waktu yang digunakan tidak ditentukan secara spesifik sehingga tercakup semua publikasi yang diindex dari awal mula publikasi SSCM sampai tanggal 30 April 2017.

\subsubsection{Pemilihan Kata Kunci}

SCOPUS menyimpan basis data dokumen dengan berbagai topik dan jenis. Pemilihan kata kunci perlu dilakukan untuk mendapatkan dokumen-dokumen yang relevan. Penyaringan dilakukan dengan mencari dokumen yang memiliki kriteria kriteria tertentu. Kriteria dalam pencarian meliputi kategori document, author, affiliation, dan advanced, dengan berbagai pilihan lokasi, misal di keseluruhan dokumen, atau judul, atau abstrak, atau kata kunci, atau judul, abstrak dan kata kunci serta bisa divariasikan dan dikombinasi pencariannya sehingga memudahkan alternatif pencarian berbagai info sesuai kebutuhan. Misal untuk pencarian pada judul (TITLE), abstrak (ABSTRACT) dan kata kunci (KEYWORD) bisa menggunakan query "TITLE-ABS-KEY".

Pencarian awal dilakukan dengan memasukkan kata kunci umum yang diinginkan untuk mencari data mengenai perkembangan ilmu SSCM di dunia. Pencarian selanjutnya dilakukan dengan berbagai kriteria yang diinginkan. Pencarian dokumen terkait penelitian tentang SSCM di Indonesia juga dilakukan untuk mengetahui 
perkembangan keilmuan ini di Indonesia. Hal ini karena masih rendahnya jumlah publikasi di bidang ini dengan country/territory Indonesia, dan perlu didorong untuk pengembangan lebih lanjut.

Tahap selanjutnya, khusus untuk publikasi di Indonesia dilakukan pencarian pada website SINTA Science and Technology Index dari Kementerian Riset, Teknologi dan Pendidikan Tinggi, Republik Indonesia.

\subsection{Rekapitulasi Literature Review Kajian SSCM}

Rekapitulasi dilakukan terhadap beberapa literature review terpilih untuk mengetahui tren keilmuan SSCM. Literature review bersumber dari publikasi yang terindex SCOPUS dan dipilih yang sesuai.

\section{Hasil dan Analisis}

\subsection{Perkembangan SSCM di dunia}

Pencarian awal dilakukan dengan memasukkan kata kunci "( TITLE-ABS-KEY ( "supply chain management" ) AND TITLE-ABS-KEY ( sustainability OR sustainable ) )" menghasilkan publikasi berjumlah 2.153 dokumen. Dengan jumlah publikasi pada tahun 2008 sebanyak 90, yang cenderung meningkat, tahun 2016 sebanyak 343 dan selama tahun 2017 sampai dengan akhir bulan April 2017 sebanyak 115. Berdasarkan hasil pencarian tersebut dibuat rangking terkait beberapa kriteria seperti ditunjukkan pada Tabel 1.

Tabel 1. Ranking berdasarkan kategori sumber dokumen, negara, afiliasi dan penulis

\begin{tabular}{|c|c|c|c|c|}
\hline \multirow[t]{2}{*}{ Ranking } & \multicolumn{4}{|c|}{ Kategori } \\
\hline & Sumber dokumen (jumlah) & Negara (jumlah) & Afiliasi (jumlah) & Penulis (jumlah) \\
\hline 1 & $\begin{array}{l}\text { Journal Of Cleaner Production } \\
\text { (114) }\end{array}$ & $\begin{array}{l}\text { United States } \\
(423)\end{array}$ & $\begin{array}{l}\text { Hong Kong } \\
\text { Polytechnic } \\
\text { University (36) }\end{array}$ & Seuring, S. (33) \\
\hline 2 & $\begin{array}{l}\text { International } \quad \text { Journal } \\
\text { Production Economics }(65)\end{array}$ & $\begin{array}{l}\text { United Kingdom } \\
\text { (243) }\end{array}$ & $\begin{array}{l}\text { Universitat } \\
\text { Kassel (31) }\end{array}$ & Sarkis, J. (27) \\
\hline 3 & Supply Chain Management (58) & China (225) & $\begin{array}{l}\text { Syddansk } \\
\text { Universitet (29) }\end{array}$ & Govindan, K. (22) \\
\hline 4 & $\begin{array}{l}\text { International Journal } \\
\text { Production Research (37) }\end{array}$ & Germany (161) & $\begin{array}{l}\text { Cardiff } \\
\text { University }(25)\end{array}$ & Jabbour, C.J.C. (15) \\
\hline 5 & Sustainability Switzerland (32) & India (120) & $\begin{array}{l}\text { University of } \\
\text { Sheffield }(20)\end{array}$ & $\begin{array}{l}\text { Gunasekaran, A. (12) } \\
\text { Searcy, C. (12) }\end{array}$ \\
\hline 23 & & Indonesia (28) & & \\
\hline
\end{tabular}

Sumber: Website SCOPUS yang diolah, 30 April 2017

Berdasarkan hasil pencarian dengan kata kunci yang digunakan, diketahui pula bahwa publikasi mengenai SSCM pertama kali pada tahun 1995. Namun hingga tahun 2000 publikasi mengenai SSCM masih di bawah 10 dan setelah tahun 2009 publikasi sudah di atas 100 publikasi per tahun. Dari Tabel 1 diketahui bahwa:

a. Publikasi yang paling banyak di Journal of Cleaner Production, 114 dokumen.

b. Negara terbanyak dari publikasi adalah Amerika, 423 dokumen.

c. Afiliasi terbanyak Hong Kong Polytechnic University, 36 dokumen.

d. Penulis terbanyak adalah Seuring, S., 33 dokumen.

Indonesia berada di urutan ke-23 di dunia dengan publikasi sebanyak 28. Ini menunjukkan bahwa publikasi tentang SSCM dari Indonesia, masih cukup rendah, sekitar seperdelapan dari negara Asia dengan publikasi terbanyak, yaitu China. Berdasarkan pengelompokan dalam 2 rentang dasa warsa, yaitu 1997-2006 dan 20072016, diketahui bahwa terjadi pergeseran dalam subject area yang terkait dengan SSCM. Hasil pengelompokan tersebut ditunjukkan pada Tabel 2.

Tabel 2. Subject area terkait dalam rentang 2 dasawarsa, 1997-2006 dan 2007-2016

\begin{tabular}{lll}
\hline \multirow{2}{*}{ Rangking } & \multicolumn{1}{c}{ Subject area } \\
\cline { 2 - 3 } & \multicolumn{1}{c}{ Tahun 1997-2006 (jumlah) } & \multicolumn{1}{c}{ Tahun 2007-2016 (jumlah) } \\
\hline 1 & Engineering (84) & Business, Management and Accounting (861) \\
2 & Business, Management and Accounting (76) & Engineering (672) \\
3 & Environmental Science (30) & Decision Sciences (395) \\
4 & Computer Science (25) & Computer Science (379) \\
5 & Decision Sciences (19) & Environmental Science (353) \\
6 & Social Sciences (19) & Social Sciences (262) \\
7 & Agricultural and Biological Sciences (15) & Economics, Econometrics and Finance (243) \\
8 & Economics, Econometrics and Finance (10) & Energy (199) \\
9 & Materials Science (9) & Agricultural and Biological Sciences (97)
\end{tabular}


Tabel 2 menunjukkan adanya pergeseran subject area dalam rentang 2 dasawarsa, 1997-2006 dan 20072016. Ini terjadi misalnya pada rangking tertinggi "Engineering" bergeser ke "Business, Management and Accounting". Ini berarti kajian SSCM semakin menarik dalam subject area "Business, Management and Accounting". Pergeseran subject area lain menunjukkan perubahan kecenderungan subject area itu terkait kajian SSCM, seperti yang mencolok terlihat pada "Energy" di mana terjadi peningkatan 2 peringkat dan peningkatan jumlah publikasi hampir 29 kali lipat.

\subsection{Perkembangan SSCM di Indonesia}

Dengan melakukan filter terhadap pencarian awal dengan membatasi khusus untuk Indonesia, maka diperoleh hasil seperti ditunjukkan pada Tabel 3. Dari Tabel 3 diketahui bahwa subject area "Engineering" masih menduduki peringkat tertinggi.

Tabel 3. Subject area terkait khusus untuk Indonesia

\begin{tabular}{ll}
\hline Rangking & \multicolumn{1}{c}{ Subject area (jumlah) } \\
\hline 1 & Engineering (14) \\
2 & Business, Management and Accounting (10) \\
3 & Computer Science (7) \\
4 & Decision Sciences (6) \\
5 & Agricultural and Biological Sciences (4) \\
6 & Economics, Econometrics and Finance (3) \\
7 & Environmental Science (3) \\
8 & Social Sciences (3) \\
9 & Materials Science (2) \\
10 & Mathematics (2) \\
\hline
\end{tabular}

Sumber: Website SCOPUS yang diolah, 30 April 2017

Pencarian berikutnya pada website SINTA Science and Technology Index dari Kementerian Riset, Teknologi dan Pendidikan Tinggi. Pencarian dokumen dilakukan dengan mengetikkan kata kunci pada form pencarian "Article Title" dicoba untuk mendapatkan publikasi terkait SSCM. Dengan keterbatasan fasilitas pencarian, maka dipilih kata kunci yang lebih umum, misal "supply chain management" dan kemudian dipilih publikasi yang kira-kira relevan dari judulnya. Tabel 4 menunjukkan jumlah publikasi dengan menggunakan kata kunci tertentu.

Tabel 4. Jumlah publikasi pada pengindex SINTA dengan kata kunci tertentu

\begin{tabular}{|l|c|}
\hline Kata Kunci & Jumlah publikasi \\
\hline supply chain management & 7 \\
\hline manajemen rantai pasok & 2 \\
\hline
\end{tabular}

Sumber: Website SINTA yang diolah, 1 Mei 2017

\subsection{Tren Keilmuan Kajian SSCM}

Pencarian tren keilmuan SSCM dapat dilakukan dengan menginventarisasi hasil publikasi- publikasi literature review tentang SSCM secara umum. Dengan mengakses website SCOPUS dan menggunakan keywords ( TITLE ( "supply chain management") AND TITLE ( sustainable OR sustainability) AND TITLE ( review) ) diperoleh 23 publikasi dan selanjutnya dipilih literature review tentang SSCM secara umum, yang bukan review suatu sektor industri, dan disampaikan topik-topik pengembangan SSCM. Literature review yang terpilih yaitu: Seuring (2013), Alexander dkk (2014) dan Liu dkk (2017) dengan topik-topik terkait SSCM ditunjukkan pada Tbel 5.

\section{Pembahasan}

Berdasarkan analisis pada bagian Perkembangan SSCM di dunia, diketahui Indonesia masih tertinggal jauh dari negara lain. Indonesia sebagai negara agraris dengan potensi alam yang besar dan dengan jumlah penduduk yang sangat besar merupakan potensi yang besar. Pemanfaatkan SSCM dalam bisnis dan perekonomian di Indonesia diharapkan dapat meningkatkan efektivitas dan efisiensinya walaupun ada kendala terkait jumlah pulau yang begitu banyak, sarana transportasi yang kurang bagus, dengan latar belakang sosial ekonomi yang 
beragam. Dari kasus-kasus nyata di lapangan, dapat dicarikan solusi yang sesuai dan terdapat potensi pengembangan riset di bidang ini.

Berdasarkan pergeseran subject area dalam rentang 2 dasawarsa yang diamati, "Business, Management and Accounting" lebih mendapatkan perhatian, karena rantai pasok yang memperhatikan aspek lingkungan dan yang peduli sosial harus tetap menguntungkan secara bisnis untuk menjamin keberlanjutannya. Peningkatan perhatian terhadap lingkungan dan sosial, justru harus bisa meningkatkan keuntungan dan bukan menambah beban biaya. Peningkatan jumlah dokumen yang meningkat drastis dengan topik SSCM "Energy" menunjukkan semakin pentingnya masalah dan riset di bidang ini untuk masa mendatang.

Tabel 5. Beberapa tren topik terkait SSCM dari Literature review terpilih

\begin{tabular}{|c|c|c|c|}
\hline Publikasi & Seuring (2013) & Alexander et al. (2014) & Liu et al (2017) \\
\hline Tema & Pemodelan SSCM & Teori Keputusan dalam SSCM & SSCM Jasa \\
\hline \multirow{12}{*}{ Topik } & $\begin{array}{l}\text { Model development considering } \\
\text { Sustainability dimensions }\end{array}$ & Pricing and cost & $\begin{array}{l}\text { The triple bottom line's interaction to the } \\
\text { ternary relation }\end{array}$ \\
\hline & $\begin{array}{l}\text { Closed-loop supply chain } \\
\text { management and reverse logistics }\end{array}$ & Inventory & The mechanism of the interaction \\
\hline & $\begin{array}{l}\text { Supply chain contracts with } \\
\text { Sustainability issues }\end{array}$ & $\begin{array}{l}\text { Supply Chain/Supply Network } \\
\text { Design }\end{array}$ & $\begin{array}{l}\text { The standardization of services in the supply } \\
\text { chain strategy, }\end{array}$ \\
\hline & Strategic supply chain design & Supplier Selection & Chain relationship management, \\
\hline & $\begin{array}{l}\text { Supply chain performance and } \\
\text { collaboration }\end{array}$ & Logistics & Customer satisfaction and supplier support, \\
\hline & $\begin{array}{l}\text { Supply chain network design against } \\
\text { environmental criteria }\end{array}$ & Environmental Management & Supply chain risk, \\
\hline & & Supply Chain Risk Management & Profit-sharing tripartite issues \\
\hline & & Supplier Performance Assessment & Service supply chain's green operation \\
\hline & & Life Cycle Analysis & Management system's construction \\
\hline & & $\begin{array}{l}\text { Closed-loop, Product Recovery and } \\
\text { Recycling }\end{array}$ & $\begin{array}{l}\text { Design a supply chain that leads to a new } \\
\text { demand for a coordination framework }\end{array}$ \\
\hline & & & $\begin{array}{l}\text { Social responsibility and economic responsibility } \\
\text { under the dual constraints of organizational } \\
\text { relationship management }\end{array}$ \\
\hline & & & $\begin{array}{l}\text { Ternary relationship under service supply chain } \\
\text { planning requirements and incentive-oriented } \\
\text { life cycle assessments }\end{array}$ \\
\hline
\end{tabular}

Subject area terkait SSCM di Indonesia menunjukkan 2 peringkat teratas seperti urutan di dunia dasawarsa sebelumnya. Dari website SINTA baru mencakup jumlah yang sangat sedikit menunjukkan dokumen terkait SCM di Indonesia masih sedikit dan efektifitas SINTA sebagai website pengindeks belum cukup efektif. Hal ini karena website SINTA masih mengandalkan keaktifan penulis untuk mengupload dokumen yang dihasilkan.

Dari literture review terpilih dari hasil pencarian di SCOPUS topik-topik keilmua yang banyak dikembangkan di bidang SSCM. Topik-topik tersebut bisa diguanakan untuk memberi arah ke mana riset di bidang SSCM sebaiknya dilakukan.

\section{Kesimpulan}

Bidang kajian SSCM (Sustainable Supply Chain Management) merupakan bidang kajian yang masih terus berkembang dan menarik untuk diteliti yang peningkatan jumlah publikasi yang terus-menerus di bidang SSCM. Perlunya perhatian bahwa peningkatan perhatian terhadap aspek sosial dan lingkungan haruslah mampu meningkatkan manfaat dari segi bisnisnya. Perkembangan publikasi bidang SSCM di Indonesia masih cukup rendah, bila dibandingkan negara lain padahal potensi pengembangan keilmuan dan bisnis dengan penerapan SSCM sangat besar. Website SINTA mengindeks dokumen SCM di Indonesia juga masih sangat rendah. Ini tantangan bagi Indonesia untuk mengejar ketertinggalannya. Topik-topik dari literture review terpilih di bidang SSCM bisa diguanakan untuk memberi arah ke mana riset di bidang SSCM sebaiknya dilakukan.

\section{Daftar Pustaka}

Ahi, P., dan Searcy, C. (2013). A comparative literature analysis of definitions for green and sustainable supply chain management, Journal of Cleaner Production Vol 52, pp. 329-341.

Alexander, A., Walker, H., dan Naim, M. (2014). Decision theory in sustainable supply chain management: a literature review, Supply Chain Management: An International Journal, Vol. 19 No. 5/6, pp. 504-522, https://doi.org/10.1108/SCM-01-2014-0007 . 
Blicharska ,M., Angelstam, P., Elbakidze, M., Axelsson, R., Skorupski, M., dan Węgiel, A. (2012). The Polish Promotional Forest Complexes: objectives, implementation and outcomes towards sustainable forest management?, Forest Policy and Economics Vol. 23, pp. 28-39.

Brandenburg, M., Govindan, K., Sarkis, J. dan Seuring, S. (2014). Quantitative models for sustainable supply chain management: Developments and directions, European Journal of Operational Research Vol. 233, pp. 299-312.

Brundtland Commission, 1987, "Report of the World Commission on Environment and Development". United Nations.

Burnham, J. F. (2006). Scopus database: a review. Biomedical digital libraries, Vol. 3 No. 1, pp. 1-8.

Chi, T. (2011). Building a sustainable supply chain: an analysis of corporate social responsibility (CSR) practices in the Chinese textile and apparel industry, The Journal of The Textile Institute Vol. 102, No. 10, pp. 837-848.

Fingerman, S. (2006). Web of Science and Scopus: Current features and capabilities. Issues in Science and Technology LibrarianshiVol. 48(Fall). Retrieved from http://www.istl.org/06-fall/electronic2.html

Gopal, P.R.C. dan Thakkar, J. (2015). Development of composite sustainable supply chain performance index for the automobile industry, International Journal of Sustainable Engineering, Vol. 8 No. 6, pp. 366-385, DOI: $10.1080 / 19397038.2014 .947392$

Govindan, K., Khodaverdi, R., dan Jafarian, A. (2013). A fuzzy multi criteria approach for measuring sustainability performance of a supplier based on triple bottom line approach, Journal of Cleaner Production Vol. 47, pp. 345-354.

Hollos, D., Blome, C., dan Foerstl, K. (2012). Does sustainable supplier co-operation affect performance? Examining implications for the triple bottom line, International Journal of Production Research, Vol. 50, Issue 11, pp. 2968-2986, DOI:10.1080/00207543.2011.582184.

United Nations, 2014, Prototype Global Sustainable Development Report, New York: United Nations Department of Economic and Social Affairs, Division for Sustainable Development, July 2014

Gimenez, C., Sierra, V., dan Rodon, J. (2012). Sustainable operations: Their impact on the triple bottom line, International Journal of Production Economics Vol. 140 pp. 149-159 doi:10.1016/j.ijpe.2012.01.035.

Hahn, R., dan Kühnen, M. (2013). Determinants of sustainability reporting: a review of results, trends, theory, and opportunities in an expanding field of research, Journal of Cleaner Production Vol. 59, pp. 5-21.

Halim, Z., 2010, Literature Review and Future Directions in SCM Research. Proceedings of the 2010 International Conference on Industrial Engineering and Operations Management. pp. 9-10 (Dhaka, Bangladesh, 9 - 10 Januari 2010).

Hall, J., Matos, S., dan Silvestre, B. (2011). Understanding why firms should invest in sustainable supply chains: a complexity approach, International Journal of Production Research Vol. 50, No. 5, 1332-1348. DOI:10.1080/00207543.2011.571930.

Høgevold, N.M. (2011). A corporate effort towards a sustainable business model: A case study from the Norwegian furniture industry, European Business Review, Vol. 23 No. 4, pp. 392-400.

Hsueh, C. F. (2015). A bilevel programming model for corporate social responsibility collaboration in sustainable supply chain management, Transportation Research Part E: Logistics and Transportation Review, Vol.73, pp. 84-95.

Jakhar, S.K. (2015). Performance evaluation and a flow allocation decision model for a sustainable supply chain of an apparel industry, Journal of Cleaner Production Vol. 87, pp. 391-413.

Lindner, M., Suominena, T., Palosuoa, T., Garcia-Gonzaloa, J., Verweijb, P., Zudina, S., dan Päivinena, R. (2010). ToSIA - A tool for sustainability impact assessment of forest-wood-chains, Ecological Modelling Vol. 221, pp. 2197-2205.

Liu, W., Bai, E., Liu, L., dan Wei, W. (2017). A Framework of Sustainable Service Supply Chain Management: A Literature Review and Research Agenda. Sustainability, Vol. 9 No. 3), 421, hal. 1-25.

Nagurney, A. dan Nagurney, L.S. (2010). Sustainable supply chain network design: a multicriteria perspective, International Journal of Sustainable Engineering, Vol. 3 No. 3, pp. 189-197, DOI: 10.1080/19397038.2010.491562.

Nepstad, D., Irawan, S., Bezerra, T., Boyd, W., Stickler, C., Shimada, J., ... \& Azevedo, A. (2013). "More food, more forests, fewer emissions, better livelihoods: linking REDD+, sustainable supply chains and domestic policy in Brazil, Indonesia and Colombia", Carbon Management, Vol 4 No. 6, pp. 639-658.

Pagell, M., dan Shevchenko, A. (2014). Why Research In Sustainable Supply Chain Management Should Have No Future, Journal of Supply Chain Management, Vol. 50 No. 1, pp. 44-55. 
Piotrowicz, W., 2011, "Monitoring Performance" dalam Sustainable Supply Chain Management: Practical Ideas for Moving Towards Best Practice, diedit oleh Cetinkaya, B., Cuthbertson,R., Ewer, G., KlaasWissing, T., Piotrowicz, W., dan Tyssen, C, Heidelberg: Springer-Verlag Berlin.

Rondon, X.J., Gorchov, D.L., dan Elliott, S.R. (2010). Assessment of economic sustainability of the strip clearcutting system in the Peruvian Amazon, Forest Policy and Economics Vol. 12, pp. 340-348.

SCOPUS (https://www.scopus.com) diakses pada tanggal 30 April 2017.

Seuring, S. (2013). A review of modeling approaches for sustainable supply chain management, Decision Support Systems Vol. 54 No. 4, pp.1513-1520.

SINTA (http://sinta1.ristekdikti.go.id/index.php?ref=home) diakses pada tanggal 1 Mei 2017. 